\title{
O PROCESSO DE ENSINAR COMPETÊNCIAS PARA PROMOÇÃO DA SAÚDE
}

\section{THE PROCESS OF TEACHING COMPETENCIES FOR HEALTH PROMOTION}

\section{EL PROCESO DE ENSEÑANZA DE COMPETENCIAS PARA PROMOCIÓN DE LA SALUD}

\author{
Luciana Netto ${ }^{1}$, Kênia Lara Silva ${ }^{2}$, Marília dos Santos Rua ${ }^{3}$, Roseni Rosângela de Sena ${ }^{4}$ (in memoriam)
}

\section{RESUMO}

Objetivo: analisar as posturas pedagógicas e estratégias de ensino utilizadas para abordagem das competências para promoção da saúde na formação de enfermeiros. Método: Estudo de caso, ancorado na dialética. Resultados: 0 currículo apresenta estratégias pedagógicas diferenciadas que podem funcionar como dispositivo para o desenvolvimento de competências para a promoção da saúde mediante uma educação multidimensional transformadora. Foram citadas: aulas teórico-práticas, construção de perguntas ou questões sobre textos, estudos dirigidos, narrativa, plenária orientada, jogos e aplicativos para celular e computador, dramatização, oficinas, estudos de caso, seminário integrado, projetos de extensão e pesquisa, ligas acadêmicas. A imersão na prática favorece o aprender a fazer, fazendo, o contato com o contexto de saúde da população e com a realidade da vida profissional. A Prática de Integração Ensino-serviço-comunidade e o estágio supervisionado aproximam o estudante do professor, integram o conhecimento e facilitam a aprendizagem prática e reflexiva. Conclusão: Os dispositivos da articulação teoria-prática podem perder a sua função precípua se não houver um direcionamento adequado durante as atividades práticas. Não basta alterar o formato do plano pedagógico e dos mecanismos de ensino, é imperativo mudar a essência do processo de ensino-aprendizagem, aproximando-o da real integração com a prática profissional crítica, dinâmica e socialmente contextualizada.

Descritores: Promoção da saúde; Educação baseada em competências; Enfermagem.

\section{ABSTRACT}

Objective: to analyze the pedagogical attitudes and teaching strategies used to approach competencies for health promotion in the training of nurses. Method: Case study, grounded in the dialectic. Results: The curriculum presents pedagogical strategies that can be a device for the development of competences for health promotion through a transformative multidimensional education. They were: theoretical-practical classes, construction of questions or questions about texts, directed studies, narrative, oriented plenary, games and applications for mobile and computer, dramatization, workshops, case studies, integrated seminar, extension and research projects, academic leagues. The immersion in practice favors the learning to "do-it-yourself", the contact with the population's health context and the reality of professional life. The Teaching-service-community Integration Practice and the supervised internship bring the student closer to the teacher, integrate knowledge and facilitate practical and reflective learning. Conclusion: The theory-practice joint devices may lose their prime function if there is no proper targeting during practical activities. It is not enough to change the format of the pedagogical plan and the teaching mechanisms, it is imperative to change the essence of the teaching-learning process, bringing it closer to the real integration with the critical, dynamic and socially contextualized professional practice.

Keywords: Health promotion; Competency-based education; Nursing.

\section{RESUMEN}

Objetivos: analizar las posturas pedagógicas y estrategias de enseñanza utilizadas para abordaje de las competencias para promoción de la salud en la formación de enfermeros. Método: Estudio de caso, anclado en la dialéctica. Resultados: El currículo presenta estratégias pedagógicas diferenciadas que pueden actuar como dispositivo para desarrollo de competencias para promoción de la salud mediante una educación multidimensional transformadora. Se han citado: clases teórico-prácticas, construcción de preguntas o cuestiones sobre textos, estudios dirigidos, narrativa, plenaria orientada, juegos y aplicaciones para celulares y computadoras, dramatización, oficinas, estudios de caso, seminario integrado, proyectos de extensión e investigación, aleaciones de estudiantes. La inmersión en la práctica favorece el aprendizaje de un "hacer haciendo", el contacto con el contexto de la salud de la población y con la realidad de la vida profesional. La Práctica de Integración Enseñanza-Servicio-Comunidad y la práctica supervisada acercan al estudiante del profesor, integran el conocimiento y facilitan la práctica reflexiva. Conclusión: Los dispositivos de articulación teoria-práctica pueden perder su función principal si no hay dirección adecuada durante las actividades prácticas. No basta cambiar el formato del plano pedagógico y sistemas de enseñanza, es imperativo cambiar la esencia del proceso de enseñanza-aprendizaje, acercándolo a real integración con la práctica profesional crítica, dinámica y socialmente contextualizada.

Descriptores: Promoción de la salud; Educación basada en competencias; Enfermería.

${ }^{1}$ Graduada em Enfermagem. Doutora em Enfermagem pela Universidade Federal de Minas Gerais. Docente na Universidade Federal de São João del-Rei. ${ }^{2}$ Graduada em Enfermagem. Doutora em Enfermagem pela Universidade Federal de Minas Gerais. Docente na Universidade de Minas Gerais. ${ }^{3}$ Graduada em Enfermagem. Doutora em Ciências da Saúde. Docente na Escola Superior de Saúde da Universidade de Aveiro/Portugal. ${ }^{4}$ Graduada em Enfermagem. Doutora em Enfermagem pela Universidade de São Paulo. Professora Emérita da Escola de Enfermagem da Universidade Federal de Minas Gerais (in memoriam).

Como citar este artigo:

Netto L, Silva KL, Rua MS, et al. O Processo de Ensinar Competências para Promoção da Saúde. 2018;8:e2611. [Access___]; Available in: DOI: http://dx.doi.org/10.19175/recom.v8i0.2611 


\section{INTRODUÇÃO}

A reorientação dos serviços de saúde como estratégia para a promoção da saúde demanda uma atuação integral, com enfoque intersetorial e multidisciplinar que, por sua vez, desdobra-se em mudanças na formação profissional para aquisição de competências específicas. Destarte, para disseminar o conhecimento sobre os atuais paradigmas de saúde e a promoção da saúde, ampla expectativa recai sobre $\mathrm{o}$ processo de qualificação profissional $^{(1-2)}$.

No cenário nacional e internacional, há diferentes propostas de reorganização curricular para os cursos da saúde. Destacamse as propostas de integração curricular como um dispositivo para atuar, com pertinência, na diversidade e complexidade da atualidade ${ }^{(1,3)}$. A literatura indica indícios favoráveis a desenhos curriculares diferenciados e seu potencial de mudança ${ }^{(1-2)}$, mas não esclarece que fatores presentes nesses currículos potencializam o desenvolvimento de competências para atuar na promoção da saúde.

Como em outros países, no Brasil, identifica-se, ainda, insuficiente preparação e formação de recursos humanos para atuar na promoção da saúde ${ }^{(1)}$, tomando por base o quadro de competências essenciais definidas nos consensos internacionais, com destaque para o Consenso de Galway e o Projeto paneuropeu CompHP ${ }^{(4)}$. Esses instrumentos definem um conjunto de onze domínios de competências essenciais para a promoção da saúde: valores éticos, conhecimentos, advocacia em saúde, produção de mudanças, parcerias, liderança, comunicação, diagnóstico, planejamento, implementação e avaliação $^{(4)}$.

O desenvolvimento de competências para promoção da saúde na formação acadêmica do enfermeiro é um tema de incorporação incipiente e heterogênea quanto à formulação teórica. Existem espaços de aprendizagem favoráveis à abordagem da promoção da saúde, mas, ainda, há necessidade de propiciar, aos estudantes, experiências não limitadas à inserção, mas de imersão na realidade da vida profissional ${ }^{(5-6)}$.

O progresso no campo da educação e da formação profissional é evidente; no entanto, nota-se, na literatura, uma diversidade de abordagens conceituais em relação aos aspectos envolvidos no processo de ensinoaprendizagem.

Dessa forma, para este estudo, considera-se atividade educativa (atividade didática ou de ensino) a situação de aprendizagem criada pelo professor para aumentar a probabilidade de que os alunos vivam as experiências julgadas necessárias para alcançar seus objetivos educacionais ${ }^{(7)}$. São exemplos de atividades de ensino: palestra, demonstração, seminário, prática de campo, estudo dirigido, simulação, jogos didáticos, projetos, visitas, pesquisa bibliográfica e outros.

Por instrumento de ensino (ou técnica de ensino) compreende-se o uso de técnicas de trabalho individual ou em grupo, que facilite a abordagem de um tema durante uma atividade educativa, a participação ativa dos alunos e o alcance do objetivo educativo, tais como: dramatização, seminário, painel, estudo de caso, oficina, dentre outros ${ }^{(7)}$.

Por estratégia de ensino (método de ensino ou estratégia pedagógica) entende-se o caminho escolhido ou criado pelo professor, na sua prática educativa, para direcionar o aluno com objetivo de motivá-lo a compreender, assimilar e aplicar conteúdos, para facilitar o processo de aprendizagem. São considerados métodos de ensino: exposição oral ilustrada ou com discussão, práticas em campo e laboratório, uso de recursos audiovisuais, excursão, dentre outros ${ }^{(7)}$.

Prática de ensino (ou práticas pedagógicas) consiste em uma complexa prática social, mediada pela interação professor-aluno-conhecimento, que acontece em diversos espaços/tempos no cotidiano dos espaços pedagógicos ${ }^{(7)}$.

Espaço de ensino (ambiente de aprendizagem ou espaço pedagógico) consiste no lócus, cultural e socialmente construído, destinado a promover oportunidades de aprendizagem $^{(7)}$.

Para ensinar competências para promoção da saúde, os educadores devem desenvolver ações educativas criativas, significativas e desafiadoras, que favoreçam a reflexividade e que promovam, no estudante, as suas potencialidades para pensar em 
soluções apropriadas aos problemas cotidianos vivenciados nos diversos contextos da prática profissional.

É inegável a evolução no campo da promoção da saúde; contudo, a relação entre a formação e a prática profissional na promoção da saúde ainda apresenta lacunas e desafios. Acredita-se que o modelo tradicional de ensino, descontextualizado, conteudista e pouco articulado das práticas em saúde, não tem sido capaz de capacitar o profissional para atuar efetivamente na promoção da saúde, um dos eixos estruturantes do SUS ${ }^{(1)}$.

Do exposto, surge esse estudo com objetivo de analisar as posturas pedagógicas e estratégias de ensino utilizadas para a abordagem das competências para promoção da saúde na formação acadêmica do enfermeiro. Pressupõe-se que o uso de estratégias pedagógicas diferenciadas, ensinadas de forma integrada e contextualizada, ao longo da formação acadêmica, pode favorecer o desenvolvimento de competências para a promoção da saúde.

\section{MÉTODO}

Trata-se de estudo de caso, qualitativo, ancorado na dialética marxista como referencial teórico-metodológico ${ }^{(8)}$. Para a obtenção dos dados foram realizados dois grupos focais que possibilitaram a discussão dos aspectos relativos às estratégias de ensino utilizadas para a abordagem das competências para a promoção da saúde na formação do enfermeiro.

Participaram das discussões, nos encontros, 15 dos 45 docentes de uma instituição de ensino superior, situada em Minas Gerais, Brasil, sendo 11 mulheres e 04 homens, representantes de todas as unidades curriculares e períodos do curso de graduação em Enfermagem. Os docentes foram distribuídos estrategicamente, de forma a manter a heterogeneidade nos dois grupos. $\mathrm{O}$ tempo médio de trabalho dos docentes participantes, na instituição, era de 3,7 anos.

Os grupos focais tiveram uma duração total de 4 h07min e 19s. A discussão teve como questão norteadora: "quais as estratégias utilizadas para a abordagem das competências para a promoção da saúde na formação acadêmica do enfermeiro nessa instituição?".
Foi disponibilizado, aos participantes, um resumo dos domínios de competências para a promoção da saúde consensuados no CompHP, para embasamento da discussão ${ }^{(4)}$.

Para evitar identificação, cada grupo focal recebeu como codificação as letras GF (grupo focal) seguida de numeração sequencial. Não houve identificação das falas de cada docente, apenas do grupo ao qual ele participou.

O discurso falado e gravado dos encontros foi submetido à transcrição, mantendo as características das falas dos participantes e seus diversos graus de detalhe como entonação, ênfase, pausa, alterações na altura e no ritmo da fala, seguindo o modelo sugerido por $\operatorname{Kock}^{(9)}$. Os dados foram explorados com a Análise Crítica do Discurso (ACD), na perspectiva de Norman Fairclough $^{(10)}$.

Para pontuar as estratégias inovadoras do currículo, facilitar a consolidação do amplo volume de material empírico e gerenciamento de todos os dados a serem analisados, foi utilizado o software webQDA, de apoio à análise de dados qualitativos. O webQDA é um software/serviço que foi desenvolvido em parceria entre a empresa Esfera Crítica e o Centro de Investigação Didática e Tecnologia na Formação de Formadores (CIDTFF) do Departamento de Educação da Universidade de Aveiro, Portugal, utilizado, principalmente, mas não exclusivamente, como poderosa e sofisticada ferramenta na pesquisa qualitativa ou análise de dados qualitativos, pela interatividade entre os mais diversos tipos de material a ser analisado ${ }^{(11)}$.

$\mathrm{O}$ projeto de pesquisa que deu origem a esse estudo (CAAE 088863612.0.0000.5149) foi aprovado pelo COEP/UFMG (Parecer $\mathrm{n}^{\circ}$ 694.248), em $24 / 06 / 2014$, e todas as etapas desse projeto estão em concordância com a Resolução 466/2012/MS, que regulamenta a pesquisa envolvendo seres humanos.

A comunicação dos resultados do estudo obedeceu às diretrizes para relatórios de projetos de pesquisa de natureza qualitativa com uso de grupos focais disponível no COREQ (Consolidated criteria for reporting qualitative research $)^{(12)}$. 


\section{RESULTADOS E DISCUSSÃO}

Os resultados indicam que os discursos incorporam a proposta do currículo diferenciado e do uso de metodologias ativas e problematizadoras de ensino como eixo central do processo educacional. Entre as atividades pedagógicas, foram citadas: construção de perguntas ou questões sobre textos específicos, estudos dirigidos, narrativa, plenária orientada, jogos e aplicativos para celular e computador. $\mathrm{O}$ uso de alguns instrumentos de ensino foi destacado nos discursos dos docentes, como a dramatização, oficinas, estudos de caso e o seminário integrado mediante casos reais.

(1) "[...] aula expositiva, é... plenária orientada, já usei demais, muito bacana,/ agora existe algumas metodologias que o aluno tem que se aplicar e ser ativo [...] esse é o grande problema, deslocar e fazer o aluno mexer, às vezes não é tanto por característica dele, mas deficiência nossa, de fazer com que ele se mexa [...]" (GF 01)

(2) "[...] e as metodologias, [...] de aprendizagem, que é o que vocês querem saber o que que a gente usa aqui: aula expositiva, a gente usa bastante, eu tô, tenho experiência no 2 응 período de usar narrativa/ porque narrativa é muito interessante principalmente na hora que vai conhecer o cenário, onde que ele tá chegando,[...] onde eles estão, eles entram e falo assim: - agora vocês vão pegar o diário de bordo de vocês, que vocês vão fazer uma viagem, [...] eu quero que vocês, livremente, escrevam o que vocês estão observando e, depois, eu quero que vocês coloquem o que vocês acharam desta/ que esta é a comunidade que a gente vai estar envolvido no semestre e vai fazer." (GF 01)

Os achados revelam que a proposta curricular apresenta estratégias pedagógicas que podem funcionar como dispositivo para o desenvolvimento de competências para a promoção da saúde mediante uma educação multidimensional transformadora. Os participantes relatam um conjunto de atividades e instrumentos de ensino que utilizam na sua prática docente e que consideram favoráveis à abordagem da promoção da saúde.

(3) "Porque, para desenvolver essas/ competências que são essenciais para a promoção da saúde/ quais são as estratégias que eu adoto? / E que eu acho que no fundo a gente acaba conseguindo alguma coisa. / Primeiro, é/ eu fui beneficiada, porque eu trabalho em BPPE (Bases Psicossociais da Prática de Enfermagem) e trabalho com legislação básica do SUS. [tosse]/ Então, eu começo lá/ anterior ao SUS, da Reforma Sanitária, [...] a Constituição vem com todas as legislações./ CAIO na Política de Promoção da Saúde,/ e trabalho/ com/ a Portaria 2.488 dentro da PIESC (Prática de Integração Ensino-ServiçoComunidade) para trabalhar a Atenção Básica de Saúde./ Então, NESSE momento, eu tento fazer um/ gancho, com tudo que/ que eu dou de aula, começando por isso./ Primeiro porque o aluno tem que entender que hoje as ações são de promoção da saúde, prevenção de riscos e agravos, [...] tratamento, cura, manutenção da saúde, reabilitação, conforme necessário./ Só que fica muito distante para ele./ Porque a cultura nossa/ é médica [voz baixa], [...]. Todo mundo está pensando só no tratamento e na cura/E ação de promoção/ é mais difícil de entender para o aluno do que a de prevenção, [...] Porque/ trabalhar a prevenção com o aluno ele entende muito bem." (GF 02)

As atividades práticas em campo, desenvolvidas ao longo do curso, foram citadas como estratégia para o desenvolvimento de competências para a promoção da saúde. A unidade curricular que integra ensino-serviço-comunidade, de modo especial, e o estágio supervisionado, incluindo o internato rural, em todos os níveis de atenção, aparecem em destaque como forma de integrar o conhecimento e facilitar a aprendizagem prática e reflexiva da promoção da saúde, no processo de formação do enfermeiro, como explicitado nos excertos:

(4) "Casos com um grupo de gestantes, que nós fizemos na semana passada/ e retrasada, um grupo de gestantes, / a gente TRABALHA essas questões de promoção. / Então, eu percebo que/ NO ALUNO/ o PIESC oportuniza isso." (GF 02)

(5) "As nossas experiências, elas/ são de PIESC. / Eu penso que onde que o aluno está mais propício a desenvolver essas competências? / Onde ele materializa tudo aquilo que ele está aprendendo ou que ele está vivendo? É assim a nossa prática profissional/Nós materializamos na nossa PRÁTICA/ aquilo que nós fomos recebendo enquanto instrumento,/ seja teórico,/ seja prático. Dento da universidade, a materialização dessas práticas, / a meu ver, ela/ está muito concentrada na PIESC, [...]. É o momento da 
integração, é o momento do raciocínio clínico, é o momento de fazer a gestão, é o momento de liderar, é o momento de ser liderado, é o momento de formar equipe, é o momento de destruir a equipe [risos], [...] Que isso também acontece. [falando pausadamente]" (GF 02)

(6) "Então, eu acho que muito do que a gente discute na PIESC, eu acho que/ que é o elo mesmo, que é ele que consegue resgatar esta questão da promoção, é a PIESC, [...], até para facilitar quando ela coloca, quando ela pede a esse aluno pra resgatar o que que ele viu/ vivenciou lá na prática, [...], quer dizer, facilita até o pessoal que está lá na/ na teoria." (GF 01)

As aulas teórico-práticas ministradas ao longo do curso, também, foram citadas como atividade estimuladora do desenvolvimento de competências para a promoção da saúde. Algumas unidades curriculares e disciplinas optativas foram destacadas pelos participantes, haja vista a importância de se trabalhar determinados conteúdos específicos, principalmente de educação em saúde, políticas públicas e legislação em saúde, para fomentar as atividades práticas junto à população. Uma unidade curricular é destacada como espaço para o desenvolvimento dos domínios de conhecimentos e ética, transversais às competências para a promoção da saúde.

(7) "[...] segunda coisa que eu acho, todas as unidades curriculares são fantásticas, mas eu acho que as bases psicossociais, ela é o ESPAÇO que a gente tem para fazer esse [...] pensar [...] SABER SER do aluno." (GF 01)

A integração entre teoria e prática, a possibilidade de aproximação com outros cursos da saúde e a proximidade com o professor são destacados pelos docentes como fatores fundamentais para avançar na formação do enfermeiro, incluindo o processo de desenvolvimento de competências para a promoção da saúde.

(8) "Eu acho/ eu vejo DUAS coisas que nosso currículo consegue é/ é [...] promover a/ promover não, [...] porque promover a promoção, / fica complicado, [voz baixa] / mas que ele [comentários paralelos entre participantes] CAMINHA na direção/ de garantir/ eu vejo duas coisas importantes. / Eu acho que primeiro:/ ele/ quebra a lógica de ciclo básico, [...] [nesse momento outra docente sinaliza que concorda com a colocação da participante] com ciclo/ profissional, [...]" (GF 02)

A participação em projetos de extensão e pesquisa, citada como atividade comum aos estudantes, é valorizada para o desenvolvimento de competências para a promoção da saúde. Os projetos de extensão, Ligas Acadêmicas e PET (Programa de Educação Tutorial) encontram destaque, pois, apesar das dificuldades de implementação, quando acontecem, permitem complementar a aprendizagem do estudante, reforçando algumas competências e favorecendo sua autonomia. Ênfase, também, é dada à iniciação científica e à elaboração do Trabalho de Conclusão de Curso.

As estratégias que permitem a aproximação com a realidade dos contextos de saúde da população e da vida profissional oportunizam, ao estudante, maior possibilidade de desenvolver competências para a promoção da saúde, como mostra os excertos:

(9) "Então, quando eu vou desenvolver uma pesquisa, eu TENTO colocar/ o que inclui também a promoção e a prevenção de riscos, [...] a promoção da saúde e a prevenção de riscos e agravos. / $E$, no cotidiano do ensino, eu/ eu TENTO fazer com/ com que isso aconteça." (GF 02)

(10) "A gente/ também, / a minha área, eu estou na área do idoso, / trabalha bastante com a promoção da saúde, [...] principalmente quando a gente vai para os/ para os ASILOS aí, / tanto com o grupo da extensão, quanto com o grupo do PIESC. [...] A GENTE PECA UM POUCO aqui, / eu acho que todas as disciplinas aqui, na minha visão, até hoje, [...] Que a gente não CONSEGUE, eu não consigo fazer/ nas outras disciplinas, nas outras atividades, na extensão tenho conseguido mais, / e aí, até agora, [...]" (GF 02)

(11) "Mas eu acho que as outras/ que as outras/ por exemplo, a "comunicação", [tosse] é/ o "planejamento", elas/ a gente consegue/ fazer isto na extensão, [...]" (GF 02)

Os discursos dos participantes indicam que aprender a fazer, fazendo, é a melhor forma de desenvolver competências para a promoção da saúde. A imersão precoce do estudante na realidade dos serviços de saúde acontece no cenário do estudo, com contato direto com a população, o que potencializa o desenvolvimento de competências para a 
promoção da saúde na formação do enfermeiro desde o primeiro período do curso.

(12) "Eu acho que quando a gente expõe, [...], vamos supor/ é [...]/ a palavra certa não é expor, a palavra certa é quando a gente OPORTUNIZA esse cenário é/ da ida/ ida mais RÁPIDO pro cenário de prática/[...] isso favorece muito. / [...] Isso favorece muito porque/ o aluno ele choca a sua realidade. [...] Acho que esta questão da IDA mais cedo ela é importante desde que atrelada com o que IRÁ FAZER [...]". (GF 01)

Na textualidade (microanálise da prática discursiva), o elemento da ACD que mais se destacou foi a metáfora ${ }^{(10)}$. Para além de ser um recurso do discurso oral, nota-se que a metáfora foi usada nas fontes de dados empíricos.

O recurso da metáfora foi utilizado para expressar a dificuldade do professor e aluno em trabalhar com o "novo", com uma proposta pedagógica diferente das que foram formadas por outras gerações de profissionais. Os discursos mostram que os envolvidos no processo querem mudar o modelo de ensino, mas os discursos remetem ao fato de que, ainda, há resquícios do modelo transmissor. $\mathrm{O}$ fato de chamar o estudante de "menino" revela esse valor intrínseco de restrição do papel protagônico do estudante no processo de ensino-aprendizagem, cujo foco, aparentemente, deve estar centrado no professor, apesar da consciência do ensino focado na participação ativa do estudante no processo. Outros recursos remetem ao ato de transmitir conhecimentos, como dar aula e fazer palestras.

(13) "[...] porque o que eu converso com os meninos o tempo inteiro é porque aluno sempre vai "chorar", isto é uma REGRA. / E a gente sempre vai falar NÃO, e a gente vai ter que ir delimitando aquele ali. / Aí, uma vez, a monitora virou para mim: ah, a aluna saiu brava com você/ [som entre língua] eu nem ligo [risos]/ eu realmente não ligo. /" (GF 01)

(14) "Ens/ensinar um potencial de ação para um aluno, gente, isso é um esforço HERCÚLEO, você demora 50 minutos para explicar para o menino que a membrana ficou mais permeável, que um íon entra e o outro sai, outro é positivo, outro está do lado de fora, e mesmo estando diferente, o menino olha aquilo ali/ foi o que a professora [...] falou, a gente demorou anos para entender, [...], e quer que o menino entenda agora/ [risos] [falas simultâneas] [nesse momento outros docentes sinalizam que concordam com a colocação da participante]./" (GF 01)

(15) "A gente tenta diversificar, com os alunos, / mas ESSA família ainda ela continua comigo, e os meninos, TODOS os meninos conhecem essa família. /"(GF 02)

(16) "[...] a (colega) colocou, [...], que lá no final alguns alunos vão se formar BEM, vão dar conta do recado e vão propor alguma coisa de promoção da saúde no estágio supervisionado e outros não vão conseguir, [...], e vocês falaram, [...], alguns professores/ agarram bem esse currículo e levam pra frente e assumem mesmo, vestem a camisa [...]" (GF 01)

$\mathrm{Na}$ análise da prática social, foi possível evidenciar que é hegemônica a ideia de que a inserção precoce no campo de prática contribui para o desenvolvimento de competências desde $\quad$ o $1^{\circ}$ período, num processo contínuo de aquisição de conhecimentos, habilidades e valores para a prática rumo à mudança do modelo assistencial. $\mathrm{O}$ contato com a população desde o primeiro período do curso, com vistas a favorecer $\mathrm{o}$ aprendizado do cuidado humanizado e a experiência de conteúdos aprendidos nas atividades teóricas é ressaltado nos discursos como fator preponderante para a formação do enfermeiro.

(17) "Então, os alunos/ é/ eles,/ desde o 10 período, eles analisam o território, conhecem o ambiente,/ conhecem as situações de saúde, as iniquidades que essa população vive e, a partir desse conhecimento, ele vai/ ESCOLHER uma família e, dentro dessa família, ele vai tentar propor mudanças ali,/ planejar a assistência desta família, é/TRAZER esta família para que ela reconheça o seu próprio problema e tentar ali empoderar/ empoderar essa família para que ela possa é/ é, DE FATO, mudar, ou aderir a/ a/ essa assistência." (GF 02)

(18) "Nós, no 2o período, trabalhamos muito com/ as práticas de alimentação saudável, [...] tanto/ na ESCOLA/ quanto [...] em visitas domiciliares e oriente ações individuais/ para a família, [...] tanto adultos quanto crianças./ E na escola [...] nós desenvolvemos, [...], além destas práticas de educação em saúde [...]/ a gente [...] desenvolve, [...] é/ sobre SEXUALIDADE, métodos contraceptivos,/ muitas vezes a gente FAZ visitas, [...], lá no CEMEI para avaliação da LINGUAGEM de crianças, [...], de 2 a 4 anos e aí nós 
trabalhamos [...] COM as crianças a prevenção de acidentes,/ tanto na ESCOLA quanto em casa." (GF 01)

A educação multidimensional transformadora é apontada pelos docentes como estratégia central para estimular, no enfermeiro, o desenvolvimento de competências essenciais necessárias para o exercício qualificado da profissão, para o pleno exercício da cidadania e bem-estar pessoal.

(19) "[...] então, assim, a gente tem muito a avançar/ [murmúrios]/ e eu acho que esse AVANÇO a gente só vai conseguir a partir do momento que a gente consiga pegar essa teoria [...], que está muito/ muito bem desenhada nas políticas, e trazer essa teoria PRÓXIMA daquele cenário [...] mas só que elas ficam muito distantes/ e a gente/, essa reflexão que a gente faz/ tem que fazer com o aluno, pra isso, pelo seguinte: no dia que ele formar, ele ser uma pessoa diferente. /" (GF 01)

$\mathrm{Na}$ busca da formação crítico-reflexiva, diversas estratégias educativas vêm sendo apresentadas como possibilidades. Dentre elas, a utilização de portfólios reflexivos ${ }^{(1,13)}$, ensino baseado na problematização ${ }^{(2,14)}$, estudos de caso, oficinas e seminários ${ }^{(7)}$. Dependendo do objetivo educativo, outras técnicas são propostas, como o uso de mapas conceituais, simulação realística, atividades de extensão e pesquisa e outras, mas, na literatura nacional e internacional, são dificilmente encontrados registros de estudos específicos direcionados ao desenvolvimento de competências para atuar na promoção da saúde.

Essas novas propostas pedagógicas que buscam a abordagem integrada, dinâmica e contextualizada do conhecimento são uma aposta no desenvolvimento crescente de autonomia $^{(14-15)}$, reflexão e teorização mediante situações da prática, avaliações sistemáticas, solidariedade, cidadania e responsabilidade social para gerar mudanças internas e externas, individuais e coletivas ${ }^{(13)}$. Essas propostas promovem, ainda, a interlocução entre ensino-serviço e comunidade, por meio de práticas integradoras articuladas aos princípios do SUS rumo a novos paradigmas ${ }^{(1)}$. Essas estratégias são indicadas como favorecedoras do desenvolvimento de competências para a promoção da saúde.

Entre as diferentes estratégias do currículo em análise, sobressaem a inserção dos alunos na realidade dos serviços e da comunidade desde os períodos iniciais, a integração curricular entre teoria e prática e entre ciclo básico e ciclo profissional. A unidade curricular PIESC congrega essas diferentes estratégias e é apresentada como a marca do curso no desenvolvimento de competências para a promoção da saúde.

As posturas pedagógicas e estratégias de ensino, utilizadas para a abordagem das competências para promoção da saúde na formação acadêmica do enfermeiro, refletem a educação multidimensional transformadora. Essa, por sua vez, busca preparar os profissionais para aprender a aprender, a saber agir e reagir com pertinência diante de situações complexas, a combinar saberes e mobilizar recursos e se envolver nos diversos contextos profissionais, como defendido por Le Boterf ${ }^{(16)}$.

Sabe-se que as estratégias pedagógicas que favorecem a integração ensino-serviçocomunidade e a imersão no contexto da prática profissional contribuem fortemente para o desenvolvimento das competências para a promoção da saúde. Na tentativa de mensurar como essas estratégias, de fato, contribuem para o desenvolvimento das competências, os achados revelam que a proposta curricular aposta na educação multidimensional transformadora.

No caso em estudo, além de oferecer condições para o desenvolvimento de competências e habilidades assistenciais, educativas, administrativas e investigativas para atendimento individual e coletivo, buscase efetivar a integração com os profissionais, os serviços de saúde e a comunidade, bem como fortalecer o SUS. Essa visão ampliada da saúde e o estabelecimento de parcerias favorecem o planejamento e a implementação de ações duradouras de promoção da saúde.

Torna-se imperativo investir na formação dos profissionais de saúde, baseado nas demandas e necessidades de saúde da sociedade brasileira e do SUS, que são extremamente dinâmicas, devido à sua determinação histórica e social $^{(17-18)}$. O 
investimento em currículos inovadores favorecidos pela articulação ensino-serviçogestão pode dar respostas a essa realidade ${ }^{(1,19)}$, o que, consequentemente, levaria ao desenvolvimento de competências para a promoção da saúde.

É preciso investir em atividades de ensino que estimulem, no enfermeiro, a capacidade de saber adaptar-se a situações complexas e inconstantes. Para isso, é necessário que a formação acadêmica seja o mais integrada, dinâmica e contextualizada ao local onde é desenvolvida ${ }^{(17)}$. Essa formação favorece a apreensão integral do saber, considerando a interdisciplinaridade, multidimensionalidade, diversidade e complexidade na sua construção, fazendo com que a integração ressalte a unidade entre as disciplinas e formas de conhecimento, levando ao perfil flexível, crítico, reflexivo, solidário, democrático, global, cidadão e transformador ${ }^{(1)}$.

Estudos mostram, ainda, que, numa instituição onde a proposta do currículo é aberta a inovações, aumenta a possibilidade de efetivação da integração ensino-serviço-gestãocomunidade $^{(1,19)}$, inserção precoce do estudante no mundo do trabalho ${ }^{(1,20)}$, atuação crítica e reflexiva, rumo à superação do paradigma conteudista. Além disso, deve-se favorecer o desenvolvimento de novas propostas pedagógicas, com utilização de metodologias ativas de ensino-aprendizagem ${ }^{(15,21)}$ e metodologias de avaliação da educação permanente, para mediar a construção do conhecimento e desenvolvimento de competências dialógicas para promoção da saúde.

Ressalta-se que não basta apenas construir um novo olhar sobre o processo saúde-doença, visando à promoção da saúde; é preciso, de fato, compreender a pessoa em sua totalidade corpo-mente; considerar $\mathrm{o}$ ambiente social, econômico, cultural e físico no qual vive, bem como seus condicionantes e determinantes da saúde e da doença, fortalecendo as estratégias que favoreçam a autonomia, a igualdade e a justiça.

Assim, compartilhando o caminho e a caminhada, transitando da tendência liberal tecnicista academicista para a progressista libertadora reflexiva ${ }^{(22)}$, romper-se-á com o paradigma da fragmentação, tornando o cenário propício à mudança de modelo assistencial, aberta à promoção da saúde.

\section{CONSIDERAÇÕES FINAIS}

Os resultados do estudo permitem uma análise, na visão do docente, das posturas pedagógicas e estratégias de ensino utilizadas para a abordagem do desenvolvimento das competências para a promoção da saúde na formação acadêmica do enfermeiro.

Além das estratégias de ensino e atividades didáticas propostas, como a prática na PIESC, o seminário integrado, a visita domiciliar e a participação em projetos de extensão e pesquisa, novas experiências nas modalidades de ensino devem ser incentivadas para mudança nos processos de ensino de enfermagem, principalmente as direcionadas ao desenvol-vimento de competências para a promoção da saúde.

No entanto, os dispositivos da articulação teoria-prática e ensino-serviço podem perder a sua função precípua se não houver um direcionamento adequado durante as atividades de campo pois, não basta alterar o formato do plano pedagógico e dos mecanismos de ensino; é imperativo mudar a essência do processo de ensino-aprendizagem, aproximando-o da real integração com a prática profissional crítica, dinâmica e socialmente contextualizada.

Apesar da distância entre o descrito teoricamente e a prática, acredita-se que a formação plurifacetada pode favorecer a reflexividade e, por conseguinte, é apontada como responsável pela mudança das práticas e do modelo assistencial vigente, ainda, centrados nas ações pseudocurativas.

Esses achados abrem espaços para futuras comparações com estudos semelhantes desenvolvidos em outros cenários nacionais e internacionais.

\section{REFERENCES}

1. Luciana Netto, Silva KL, Rua MS. Reflective practice and vocational training: Theoretical approaches in the field of Health and Nursing. Esc Anna Nery 2018 Jan;22(1):12-7. DOI: $10.1590 / 2177-9465-$ ean-2017-0309

2. Carvalho VL de, Oliveira ALC de, Alves 
IKS, Silva RL, Silva CB da. Health promotion competencies of undergraduate health professionals. Rev Enferm UFPE 2017 ago;11 (supl 8):3269-78. Disponível em: https://periodicos.ufpe.br/revistas/revistaenfer magem/article/view/110193/22082

3. Pinheiro DGM, Scabar TG, Maeda ST, Fracolli LA, Pelicioni MCF, Chiesa AM. Health promotion competencies: Challenges of formation. Saúde Soc. 2015 jan/mar;24(1):180-8. DOI: $10.1590 /$ S0104$\underline{12902015000100014}$

4. Barry MM, Battel-Kirk B, Davison H, Dempsey C, Parish R, Schipperen M, et al. The CompHP project handbooks. Paris: IUHPE; 2012. Disponível em: https://www.researchgate.net/publication/233 808334_The_CompHP_Project_Handbooks

5. Silva KL, Araújo FL de, Santos FB de O, Andrade AM, Basílio NC, Sena RR de. What has been talking on competence in health promotion in nursing education? ABCS Heal Sci. 2015;40(3):286-93. Disponível em: http://files.bvs.br/upload/S/2318-

4965/2016/v40n3/a5360.pdf

6. Luciana Netto, Silva KL, Rua M dos S. Competency building for health promotion and change in the care model. Texto Context Enferm. Texto Contexto Enferm. 2016;25(2):1-7. DOI: $\quad$ 10.1590/010407072016002150015

7. Bordenave JD, Pereira AM. Estratégias de ensino-aprendizagem. 32. ed. Petrópolis: Vozes; 2015.

8. Marx K. O capital: Pósfácio à segunda edição. 2. ed. São Paulo: Abril Cultural; 1983. 9. Kock IV. A inter-ação pela linguagem. São Paulo: Contexto; 2010.

10. Fairclough N, Mulderrig J, Wodak R. Critical discourse analysis. In: Van Dijk T, editor. Discourse studies: a multidisciplinary introduction. London: Sage; 2011. p. 357-78.

11. Costa AP, Souza FN de, Reis LP, Freitas F. Funcionalidades para a promoção do trabalho colaborativo em investigação qualitativa: O caso software webQDA. In: Proceedings of the Conference on Informations Systems and Technology, 2016; Nashville. Nashville: CIST; 2016. p. 1-8.

12. Tong A, Sainsbury P, Craig J. Consolidated criteria for reporting qualitative research (COREQ): A 32-item checklist for interviews and focus groups. Int J Qual Heal $\begin{array}{llll}\text { Care } 2007 \text { Dec;19 (6):349-57. DOI: } & \end{array}$ 10.1093/intqhc/mzm042

13. Dalla Lana L, Arend Birner J. Um relato de caso sobre a construção e elaboração do portfólio como metodologia avaliativa de aprendizagem. Cienc Enferm. 2015 Dic;21(3):101-12. DOI: $10.40 \quad 67 /$ S0717$\underline{95532015000300009}$

14. Diesel A, Leila A, Baldez S, Martins SN. Active teaching methodologies principles: A theoretical approach. Rev Thema 2017;14(1):268-88. Disponível em: http://revistathema.ifsul.edu.br/index.php/the $\underline{\mathrm{ma} / \mathrm{article} / \mathrm{view} / 404}$

15. Alves MNT, Marx M, Bezerra MMM, Landim JMM. Pedagogical methodologies active in health education. Id Line Multidiscip Psycology J Artig. 2017 Jan; 33(Suppl.

2):339-46. Disponível em:

https://idonline.emnuvens.com.br/id/article/do wnload/659/927

16. Le Boterf G. Desenvolvendo a competência dos profissionais. 3. ed. Porto Alegre: Artmed; 2007.

17. Luciana Netto, Silva KL. Between the old and new: Advances and challenges in the construction/reconstruction of the nursing courses curriculum. Rev Enferm do CentOeste Min. 2017;7:e1634. Disponível em: http://seer.ufsj.edu.br/index.php/recom/article/ download/1634/1777

18. Trindade LDL, Ferraz L, Ferraboli SF, Rubini B, Saldanha CT, Bordignon M, et al. A formação profissional na orientação da assistência aos grupos vulneráveis na atenção básica. Rev Enferm UFSM 2015 abr/jun;5(2):368-78.

$\underline{10.5902 / 2179769213738}$

19. Vendruscolo C. Teaching-service integration and its interface in the context of reorienting health education. Interface 2016 out/dez;20 (59): 1015-26. DOI: $\underline{10.15}$ 90/1807-57622015.0768

20. Velloso MP, Guimarães MBL, Cruz CRR, Neves TCC. Interdisciplinarity and training in the collective health area. Trab Educ Saúde 2016 jan/mar;14(1):257-71. DOI: $\underline{\text { 10.1590/1981-7746-sip00097 }}$

21. Simon E, Jezine E, Vasconcelos EM, Ribeiro KSQS, Simon E, Jezine E, et al. Active teaching-learning methodologies and 
popular education: agreements and disagreements in the context of health professionals' education. Interface 2014 dez;18(supl 2):1355-64. DOI: 10.1590/1807$\underline{57622013.0477}$

22. Alves E, Oliveira MAC. O desenvolvimento da competência crítica e reflexiva no contexto de um currículo integrado. Londrina: iNESCO; 2013.

Nota: Manuscrito baseado no projeto intitulado: Currículo integrado e a formação de competências para a promoção da saúde (tese de doutorado) do Programa de Pós-Graduação da EEUFMG, com estágio na Universidade de Aveiro - Portugal. Vinculado ao Projeto do Núcleo de Estudos e Pesquisas sobre Ensino e Prática de Enfermagem - NUPEPE. Financiado parcialmente pelo CNPq - Processo 204340/2014-4.

Recebido em: 13/11/2017

Aprovado em: 18/05/2018

Endereço de correspondência:

Luciana Netto

Rua Sebastião Gonçalves Coelho - 400 Sala 301.4 - Bloco D

CEP: 35501-296 - Divinópolis/MG - Brasil

E- mail: luciananetto@ufsj.edu.br 